Research Article

\title{
Can the Implied Information of Options Predict the Liquidity of Stock Market? A Data-Driven Research Based on SSE 50ETF Options
}

\author{
Hairong Cui $\mathbb{D}$, Jinfeng Fei $\mathbb{D}$, and Xunfa Lu \\ School of Management Science and Engineering, Nanjing University of Information Science and Technology, \\ Nanjing 210044, China \\ Correspondence should be addressed to Hairong Cui; cuihairong@nuist.edu.cn
}

Received 3 August 2021; Revised 11 September 2021; Accepted 15 September 2021; Published 1 October 2021

Academic Editor: Shaojian Qu

Copyright (c) 2021 Hairong Cui et al. This is an open access article distributed under the Creative Commons Attribution License, which permits unrestricted use, distribution, and reproduction in any medium, provided the original work is properly cited.

Liquidity reflects the quality of the market. When the market is short of liquidity, it often causes investors' trading difficulties and stock price volatility, expanding the investment risk. As a risk management tool, options attract more informed investors to trade because of their flexible design. To explore whether the implied information based on the formation of option price can predict the liquidity of stock market, we take SSE 50ETF options from February 9, 2015, to December 31, 2020, as the research sample. Based on the idea of data-driven approach, we extract the implied information contained in option price, including implied volatility, implied volatility spread, and variance risk premium. Through the regression analysis method, we examine the ability to predict the liquidity of the stock market. The results show that implied volatility spread has the strongest ability to predict the liquidity of the stock market, and it is more significant within 270 days. Implied volatility contains the information about the short-term (120 days) liquidity of the stock market in the future. It shows that implied volatility and implied volatility spread are good indicators to predict stock market liquidity. In contrast, variance risk premium cannot predict the liquidity of stock market. The research conclusion verifies the role of option-implied information in predicting the stock market's liquidity. By extracting the information of options price, investors and financial regulators can scientifically participate in the financial market under data guidance.

\section{Introduction}

Liquidity, volatility, and profitability are the essential attributes of the financial market, in which liquidity is in the leading position and is the blood and soul of the market $[1,2]$. When the market is short of liquidity, investors often face the problems of transaction difficulty, long transaction completion time, and high transaction cost, which reduces the operational efficiency of the securities market and is not conducive to the healthy and stable development of the market.

Although many scholars at home and abroad have studied liquidity, there is no unified concept for the definition and measurement of liquidity. Harris [3] defined the concept of market liquidity from four dimensions based on the microstructure theory. He believed that liquidity includes four dimensions in the stock market: market width, market depth, market resiliency, and immediacy. Market width represents the deviation degree of transaction price from effective market price; market depth refers to the maximum number of stocks that can be traded without affecting the current market price; market resiliency refers to the speed at which the price returns to the average level after the completion of a large number of stock transactions; immediacy measures whether investors can complete the transaction in time. In addition, some scholars began to explore which factors will affect stock liquidity.

Some common factors affect the liquidity level of all stocks in the market, making the liquidity of different stocks have a significant correlation. That is, the liquidity tendency of individual stocks improves or worsens at the same time. This phenomenon is called Commonality in Liquidity [4]. Commonality in Liquidity indicates that the liquidity of individual stocks is partly determined by the liquidity of the 
whole market. Therefore, relative to the liquidity of individual stocks, the stock market's liquidity has become one of the hot topics of scholars at home and abroad.

The liquidity of the stock market is very fragile. When the stock market falls, the liquidity will continue to decrease $[5,6]$. When the market is in crisis, the liquidity will rapidly decrease or even "evaporate" in a short time, which further leads to the rapid decline of the market and the sharp rise of transaction costs [7]. Looking at the history of world finance, we can find that the fragility of liquidity is often manifested in the form of drastic changes. For example, one of the critical characteristics of the stock market disaster in the United States in 1987 is that the whole market liquidity evaporates rapidly in a very short time. The Asian financial crisis in 1997 was also caused by the rapid decrease of liquidity. The global financial crisis in 2008 was caused by the financial market panic caused by the U.S. subprime mortgage crisis, which led to the liquidity crisis and spread rapidly in the world through the spillover effect between financial markets. As a representative of emerging markets, in recent years, in China's stock market in April 2010, June 2013, and June 2015, stock prices have plummeted. From June 8 to August 26, 2015, Shanghai Composite Index dropped from 5131.88 points to 2927.29 points, down 42.96\%, and Shenzhen Composite Index dropped from 2994.85 points to 1695.76 points, down $43.38 \%$. During this period, more than 1000 listed companies chose to suspend trading for hedging, and the stock market's liquidity almost dried up. This stock disaster is mainly reflected in the trading and systemic liquidity crisis. Therefore, investors are deeply aware that the stock market's liquidity is important for regular trading and healthy operation of the market. Information asymmetry and uncertainty usually tend to increase risks [8]. Suppose that we can predict the future liquidity of the stock market according to the relevant indicators and make timely trading adjustments. In that case, it is of great significance to prevent the huge losses caused by liquidity risk.

As a risk management tool, options attract investors with more information to trade. Unlike the spot market, option price contains the expected information of the market and investors for the future market. Therefore, compared with historical information, the implied information extracted from option price is often forward-looking and is a better prediction index [9]. Then, scholars began to explore whether these indicators can predict the stock market-related information. Nowadays, there are only two kinds of stock options in Chinese stock market. The SSE 50ETF options were launched on February 9, 2015, and the CSI 300ETF options were listed on December 23, 2019. Considering the launch time of CSI 300ETF options, the development and price information in the market is not mature enough. By contrast, the SSE 50ETF options have begun to take shape after the development in recent years, including business type, functional positioning, and regulatory system, which can provide high research values for us.

The data-driven approach is to use data as a means of production of extracted features through scientific methods and apply them to problems to be solved. Data-driven methods have certain applicability and advantages in the research of management. Chen and Wang [10] constructed a credit default estimation model under the condition of changing information asymmetry, which is applicable to the risk characteristics of micro and small enterprises. Ji et al. [11] used three different modeling methods for constructing the two-stage mean-risk stochastic minimum cost consensus models to assess the impact of risk on results. Considering the advantages of data-driven approach in solving related problems, we decided to apply this idea to the stock and option markets.

At present, most of the researches focus on the prediction of stock return and volatility, but the prediction of liquidity is rare, and the prediction index is relatively single. The markets focus on the more mature European and American markets, and the research on the Chinese market is relatively more minor. According to the above shortcomings, this paper considers the following. Firstly, based on the data of SSE 50ETF options, we calculate the implied volatility (IV), the implied volatility spread (IVS), and the variance risk premiums (VRP), respectively; analyze whether they can predict the liquidity of Chinese A-share market; and verify the daily data. Whether there is a difference between the weekly data and the monthly data is also considered. Relevant studies show that IV, IVS, and VRP are more significant than other indicators in predicting the return and volatility of the financial market and contain more information about the future of the financial market [12-17]. We have reasons to believe that these three indicators still have advantages in predicting liquidity. Secondly, considering the late start of China's option market, the data is divided into the initial stage and the development stage to verify whether the data has time-varying characteristics. Finally, by changing the calculation method of the index, we examine whether the research conclusion is robust.

The rest of the article is arranged as follows: Section 2 presents the relevant literature. Section 3 describes the related variables and sets the model. Section 4 gives the descriptive statistics and empirical analysis of the sample data to explore whether the implied information of options can predict the future liquidity of the stock market. The final section ends this paper with concluding remarks.

\section{Literature Review}

When the stock liquidity in the financial market is insufficient, the investors' willingness to hold the asset is low, and the asset's value will be undervalued. In other words, the liquidity level of financial assets will significantly affect its expected return. Therefore, the research on the liquidity of financial assets has always been the focus of academic circles. In recent years, scholars have mainly studied the stock market in the three following aspects.

2.1. Liquidity and Its Measurement. There is no unified definition of liquidity. Scholars have studied liquidity measurement from different perspectives. Demsetz [18], Black [19], and Kyle [20] proposed that bid-ask spread is an 
important index to measure market liquidity based on price method. The smaller bid-ask spread is, the smaller the transaction cost is, which means better market liquidity. Since the price method ignores the quantity factor, Grossman [21] used the transaction amount within a certain period as the index to measure the market liquidity. Since then, scholars began to combine the first two types of research and put forward the index based on the combination of price and trading volume. Martin [22] constructed the relevant index, which is composed of the square of the difference between the closing price of the day and the closing price of the previous day divided by the trading volume of the day. The larger the index, the lower the market liquidity. The illiquidity index proposed by Amihud [5] uses the ratio between the absolute value of stock return and transaction amount to measure and analyze. So far, different scholars have put forward different liquidity measurement indicators based on the research, which cover multiple dimensions of liquidity information and have specific usevalue in practical application.

2.2. Factors Affecting Liquidity. The existing papers mainly analyze the influencing factors of stock market liquidity from the micro and macro levels. According to the market microstructure, scholars analyze the influence of micro factors on stock market liquidity from different perspectives.

Ignacio et al. [23] found a positive correlation between corporate information disclosure and stock liquidity, and press conferences increase informed trading and uninformed trading. Jyoti [24] studied the relationship between stock market liquidity and investor sentiment. The irrational composite sentiment index (ASI) is constructed to measure the sentiment of institutional investors. The empirical results show that when the market sentiment is bullish, the stock market has high liquidity. Abdulrahman and Atsuyuki [25] studied the impact of emerging market stock liquidity and future investment. There is a positive correlation between future investment and stock liquidity.

Scholars who focus on the relationship between macroeconomic factors and stock market have also made a lot of achievements. Bai and Qin [26] found that market liberalization will increase the liquidity risk of emerging stock market. Cao and Kling [27] showed that the impact of policy on market liquidity has short-term timeliness, while the effects of the macroeconomic environment on financial market are minor. Basistha and Kurov [28] proved that the impact of monetary policy on the stock market changes with economic cycle change, and the impact of monetary policy on the stock market is greater during the economic recession.

\subsection{The Prediction of Stock Market Attribute by the Implied} Information of Options. Compared with the spot market, options market has a particular information advantage, which is mainly because, compared with the spot market, the benefits of high leverage and low transaction cost of the options market make many informed traders choose to trade in the options market first. New predictors can be used as an important branch of prediction development [29]. Scholars find that the implied information of options market may also have the spot market return and volatility information. Bali and Hovakimian [12] and Bollerslev et al. [13] found that the variance risk premium of options market includes the return information of future stock market. Chen et al. [14] found that the deviations from putcall parity can predict future volatility. After controlling the variables such as implied volatility, information shock, and short selling limit, the result of volatility prediction is still significant. Based on the option data of three major energy markets, Cao et al. [15] found that variance risk premium is better than other indicators in forecasting volatility. Marcel and Chardin [16] used regression analysis method to analyze individual stock and found that the implied volatility spread of individual stock options can predict the longterm equity premium of the underlying stock. Henrique and Marcelo [17] analyzed the relationship between liquidity and implied volatility, which shows that the increase of implied volatility will improve the illiquidity of the market. The research results of these scholars show that the implied information of options has a particular ability to predict the return and volatility of the future stock market, which confirms that the information of options is forward-looking relative to the spot market and is a better prediction index.

\section{Research Design and Data Description}

The complete data-driven links usually cover data acquisition, data modeling, data analysis, and data feedback. In the research and design link, the section introduces the idea of data-driven approach. Firstly, we collect the trading data published in the securities market and filter and clean them according to the requirements to get the final sample of the study. Secondly, based on the variance swap principle and Black-Scholes option pricing formula, the prediction indexes are extracted from the price information. Meanwhile, we construct the multiple linear regression model to verify the prediction effect of indicators on stock market liquidity. Finally, according to the empirical results of the model, we analyze the theoretical logic and practical significance behind them and send the analysis results to investors to make more reasonable investment.

\subsection{Variable Selection}

\subsubsection{Implied Information of Options}

(1) Implied Volatility (IV). Based on the volatility index of Shanghai Stock Exchange and variance swap principle [30], the most recent contract with a maturity of more than 7 days is called the near month contract, and next near contract is called the next month contract. The calculation formula of volatility in recent months is as follows:

$$
\sigma_{1}^{2}=\frac{2}{T} \sum_{i} \frac{\Delta K_{i}}{K_{i}^{2}} e^{r T} P\left(K_{i}\right)-\frac{1}{T}\left(\frac{F}{K_{0}}-1\right)^{2},
$$


where $\sigma_{1}^{2}$ is near month volatility; $T$ is the expiration time of the contract; $r$ is the risk-free interest rate; $K_{\mathrm{i}}$ is the strike price of the option; $F$ is the forward price, and $F=K+e^{r T}(C-P) ; C$ and $P$ represent the price of call and put options, respectively; $K$ is the minimum price difference between call and put option; $\Delta K_{\mathrm{i}}$ is the execution price interval corresponding to the execution price $i$, which is $K_{i+1}-K_{i-1} / 2 ; K_{0}$ is the first option strike price below the forward price $F$. The calculation method of next month volatility $\sigma_{2}^{2}$ is consistent with that of near month volatility.

Implied volatility is calculated using the following formula:

$$
\begin{aligned}
& \mathrm{IV}=\left[T_{1} \sigma_{1}^{2}\left(\frac{N T_{2}-N_{30}}{N T_{2}-N T_{1}}\right)+T_{2} \sigma_{2}^{2}\left(\frac{N_{30}-N T_{1}}{N T_{2}-N T_{1}}\right)\right] \times \frac{N_{365}}{N_{30}}, \\
& T_{1}=\frac{N T_{1}}{N_{365}}, \\
& T_{2}=\frac{N T_{2}}{N_{365}},
\end{aligned}
$$

where $N T_{1}$ and $N T_{2}$ are the numbers of minutes remaining after the expiration of the near month option and the next near month option, respectively; $N n$ is the number of minutes in $n$ days.

(2) Implied Volatility Spread (IVS). According to the principle of parity, implied volatility of call options should be equal to that of put options. However, in the real market, due to the existence of transaction costs, margin system, short selling mechanism, and informed trading, there are differences in the implied volatility of call and put options, which indicates that option pricing is unreasonable and there are arbitrage opportunities. Therefore, according to Cremers and Weinbaum [31], the calculation formula of implied volatility spread is as follows:

$$
\mathrm{IVS}_{t}=\mathrm{IV}_{t}^{\text {call }}-I V_{t}^{\text {put }}=\sum_{j=1}^{N_{t}} w_{j}\left(\mathrm{IV}_{j, t}^{\text {calls }}-\mathrm{IV}_{j, t}^{\text {puts }}\right),
$$

where $N_{\mathrm{t}}$ means that there are $n$ pairs of options on day $t$, and the call and put options with the same maturity and exercise price are an option pair; $W_{\mathrm{j}}$ is the weight of the open position of the pair of options $j$ on day $t$ in the total open position on day $t ; \mathrm{IV}_{j, t}^{\text {calls }}$ and $\mathrm{IV}_{j, t}^{\text {puts }}$, respectively, represent the implied volatility of the call and put options in the pair of options $j$ on day $t$.

(3) Variance Risk Premium (VRP). Empirical research shows that the implied variance of options is higher than the realized variance, reflecting the demand of investors to hedge volatility risk with options. Bollerslev et al. [32] defined variance risk premium as the difference between implied variance and realized variance, which can help investors better manage their portfolios and hedge risks. The calculation formula is as follows:

$$
\begin{aligned}
\mathrm{VRP}_{t} & =\mathrm{IV}_{t}-\mathrm{RV}_{t}, \\
\mathrm{RV}_{t} & =\sum_{i=1}^{n}\left[\ln \left(\frac{P_{t, i}}{P_{t, i-1}}\right)\right]^{2},
\end{aligned}
$$

where $\mathrm{IV}_{t}$ and $\mathrm{RV}_{t}$ are the implied variance and realized variance on day $t$, respectively; $P_{t, i}$ represents observation $i$ of the underlying asset price on day $t$.

3.1.2. Liquidity Index. At present, there is no consensus on the method of liquidity measurement in academic circles. Henrique and Marcelo [17] have summarized more than ten liquidity indicators. Among them, the illiquidity index proposed by Amihud [5] has been adopted as the measurement standard by many scholars at home and abroad. Wan et al. [33] evaluated the liquidity index and found that Amihud index performs better under price shocks. Based on the above research findings, we use the illiquidity index proposed by Amihud as the proxy variable of stock liquidity, and the smaller the Amihud value is, the better the stock liquidity is. The calculation method is as follows:

$$
\operatorname{Amihud}_{i, d}=\frac{1}{D} \sum_{d=1}^{D} \frac{\left|R_{i, d}\right|}{\operatorname{VOLD}_{i, d}} .
$$

The liquidity of the stock market is calculated as follows:

$$
\operatorname{Amihud}_{M, d}=\frac{1}{N} \sum_{t=1}^{N} \text { Amihud }_{i, d},
$$

where $R_{i, d}$ and $\operatorname{VOLD}_{i, d}$, respectively, represent the absolute value of the return rate and the transaction amount of stock $i$ on day $d ; D$ represents the transaction days; $N$ is the number of stocks normally traded on day $d$ in the market. When selecting samples, the stocks with less than 200 trading days in the previous year are excluded, and the stocks with annual liquidity of the previous year accounting for the first $1 \%$ and the last $1 \%$ of all stocks in the A-share market are excluded; the shares of ST, ST*, and PT companies are excluded.

\subsubsection{Control Variables}

(1) Risk-Free Interest Rate $\left(R_{F}\right)$. Risk-free interest rate is usually regarded as the basic interest rate of the market, which affects the expectation of investors for the return of financial assets. It affects the price and liquidity of assets in the market. We use Shanghai Interbank Offered Rate (SHIBOR) as the risk-free interest rate.

(2) Shanghai Stock Index Return (SIR). Generally, the index return often represents the overall situation of the market. When the market return is optimistic, it will attract investors to pour funds into the market and promote the liquidity of the financial market. Therefore, the Shanghai stock index return is taken as the control variable, and its calculation formula is as follows:

$$
\mathrm{SIR}_{t}=\frac{P_{t}-P_{t-1}}{P_{t-1}},
$$


where $P_{t}$ and $P_{t-1}$ represent the closing prices of Shanghai stock index on days $t$ and $t-1$, respectively.

(3) CSI Aggregate Bond Index Return (CIR). Stocks and bonds are regarded as important financial assets in the securities market, and they will interact with each other. Griffin et al. [34] found a two-way risk spillover effect between the stock market and the corporate bond market. Marcello [35] thought that there is a negative correlation between the returns of stocks and bonds. The change of CSI aggregate bond index reflects the change of bond market price. Therefore, considering the impact of the bond market on the liquidity of the stock market, CSI aggregate bond index yield is included in the control variable. The calculation formula is as follows:

$$
\mathrm{CIR}_{t}=\frac{\mathrm{IP}_{t}-\mathrm{IP}_{t-1}}{\mathrm{IP}_{t-1}},
$$

where $\mathrm{IP}_{t}$ and $\mathrm{IP}_{t-1}$ represent the closing prices of the CSI aggregate bond index on days $t$ and $t-1$, respectively.

(4) RMB Exchange Rate (ER). Long et al. [36] pointed out that the RMB exchange rate has a negative impact on Chinese stock prices. Huang et al. [37] analyzed the impact of exchange rate fluctuations on the stock market, and there are differences in the degree, direction, and duration of the impact of exchange rate fluctuations on the stock market in different countries. Relevant studies have shown that the change of RMB exchange rate directly impacts the operation of China's A-share market. In the case of RMB appreciation, investors will have more confidence in China's market and promote the liquidity of the stock market. Therefore, under the indirect pricing method, the amount of RMB convertible into US $\$ 1$ is used as the index of RMB exchange rate, which is included in the control variable. The smaller the value, the greater the external value of RMB.

3.2. Model Setting. In order to test the prediction effect of option implied information on stock market liquidity, we use the research of Henrique and Marcelo [17] for reference:

$$
\begin{aligned}
& \text { liquidity }_{t+d}=\alpha+\beta \mathrm{IV}_{t}+\gamma_{1} R_{F, t}+\gamma_{2} \mathrm{SIR}_{t}+\gamma_{3} \mathrm{ER}_{t}+\gamma_{4} \mathrm{CIR}_{t}+\varepsilon_{t}, \\
& \text { liquidity }_{t+d}=\alpha+\beta \mathrm{IVS}_{t}+\gamma_{1} R_{F, t}+\gamma_{2} \mathrm{SIR}_{t}+\gamma_{3} \mathrm{ER}_{t}+\gamma_{4} \mathrm{CIR}_{t}+\varepsilon_{t}, \\
& \text { liquidity }_{t+d}=\alpha+\beta \mathrm{VRP}_{t}+\gamma_{1} R_{F, t}+\gamma_{2} \mathrm{SIR}_{t}+\gamma_{3} \mathrm{ER}_{t}+\gamma_{4} \mathrm{CIR}_{t}+\varepsilon_{t},
\end{aligned}
$$

where liquidity $t_{t+d}$ indicates the liquidity of the stock market on day $t+d ; \mathrm{IV}_{t}, \mathrm{IVS}_{t}$, and $\mathrm{VRP}_{t}$ represent implied volatility, implied volatility spread, and variance risk premium of day $t$, respectively.

\section{Empirical Results and Analysis}

Based on the launch time of SSE 50ETF options, we select the stock and options data from February 9, 2015, to December 31,2020 , as the research sample, with a total of 1437 trading days. The data comes from CSMAR Database and RESSET Database.
4.1. Descriptive Statistical Analysis. Table 1 reports the descriptive statistics of related variables, and Figures 1-3 show the original data chart of IV, IVS, and VRP, respectively. The implied volatility fluctuated wildly in the second half of 2015, which was mainly due to the liquidity crisis in the stock market in 2015, which led to the stock disaster and the price fluctuation, and then the implied volatility tended to be stable. During the stock market crash in the second half of 2015 and the epidemic period in the first half of 2020, VRP showed a significant negative situation. During the crisis, the government often adopted the rescue measures, which is equivalent to giving the market a free put option. Therefore, in the options market, investors expect the future volatility to be rebalanced, and IV will be less than the higher RV, resulting in VRP less than 0 . The mean value of IVS is -0.023 . Most of the values are negative, which indicates that the implied volatility of put options is greater than that of call options in the SSE 50ETF options market, reflecting that investors hold more pessimistic sentiment in the selected data range. Consistent with IV and VRP, IVS fluctuated significantly in the two crisis periods and remained relatively stable in the rest of the time.

4.2. Correlation Analysis. To avoid multicollinearity among explanatory variables, Pearson correlation coefficients among variables are reported in Table 2, which are all below 0.8 . The last line of Table 2 gives the coefficient of variance expansion (VIF) of explanatory variables, which are less than 10 , indicating that there is no multicollinearity problem among explanatory variables. Therefore, the multiple linear regression model we construct can be used for subsequent empirical analysis.

\subsection{Regression Analysis}

4.3.1. Forecasting Power of IV on Stock Market Liquidity. Table 3 reports the prediction of implied volatility for the liquidity of the stock market in the short term. From the regression results, we can find that, in the short term, implied volatility has significant prediction ability for the liquidity of the stock market, and the coefficients are significant at the significance level of $1 \%$. The coefficient of IV is positive, which indicates that, with the increase of implied volatility, the greater the illiquidity index, the lower the liquidity of stock market. This may be due to the changes of the underlying assets measured by volatility. The greater the volatility is, the more unstable the asset price is, which leads to less financial assets available for trading and greater market friction. On the other hand, high volatility also reflects that investors are in a negative state on the overall sentiment of the market. Investors tend to reduce their trading frequency, and the market is not active, resulting in a low level of liquidity in the market.

The risk-free interest rate also has a particular prediction effect on the liquidity of the stock market, which is significant in the time interval of more than 30 days, and the coefficient is positive, indicating that the higher the risk-free interest rate is, the lower the overall liquidity of the market 
TABle 1: Descriptive statistics of variables.

\begin{tabular}{lcccccccc}
\hline & No. of obs. & Mean & Median & Max & Min & Std. dev. & Skewness & Kurtosis \\
\hline IV & 1437 & 0.231 & 0.211 & 0.828 & 0.081 & 0.103 & 1.623 & 7.202 \\
IVS & 1437 & -0.023 & -0.002 & 0.370 & -0.985 & 0.099 & -3.200 & 25.450 \\
VRP & 1437 & 0.029 & 0.040 & 0.258 & -0.609 & 0.088 & -2.268 \\
$R_{F}$ & 1437 & 0.009 & 0.008 & 0.014 & 0.004 & 0.002 & 0.390 \\
SIR & 1437 & 0.000 & 0.001 & 0.058 & -0.085 & 0.015 & -1.012 & 2.532 \\
ER & 1437 & 6.682 & 6.713 & 7.132 & 6.108 & 0.276 & -0.471 & 2.298 \\
CIR & 1437 & 0.018 & 0.020 & 0.728 & -0.729 & 0.079 & 0.258 & 18.004 \\
\hline
\end{tabular}

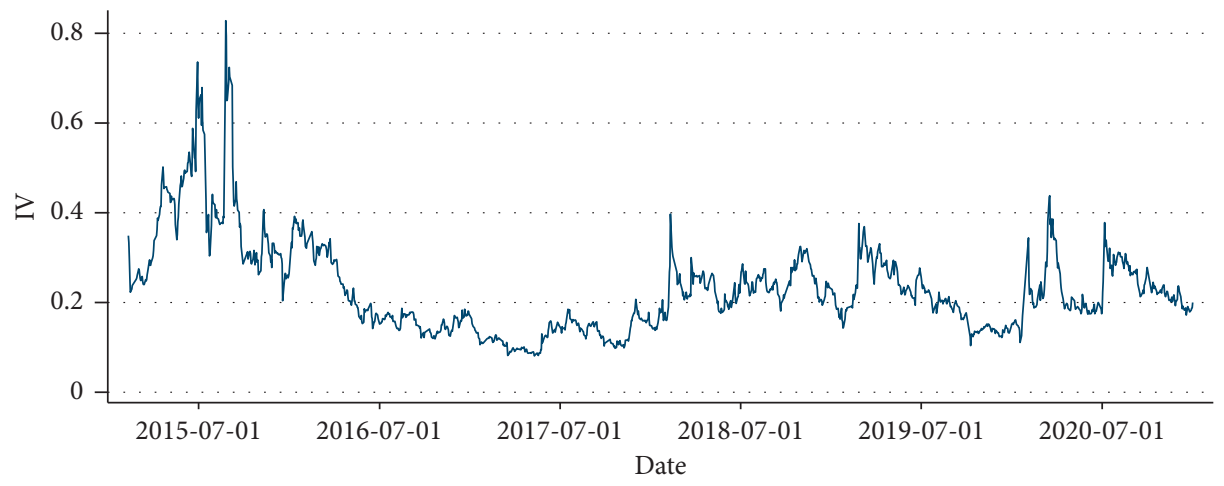

FIgURE 1: IV original data chart of SSE 50ETF options.

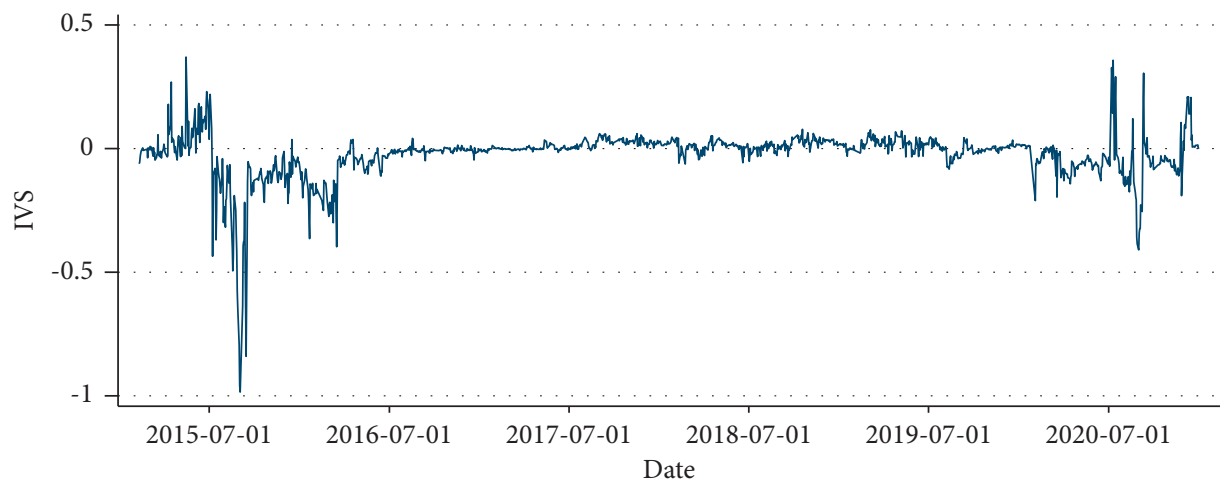

FIgURE 2: IVS original data chart of SSE 50ETF options.

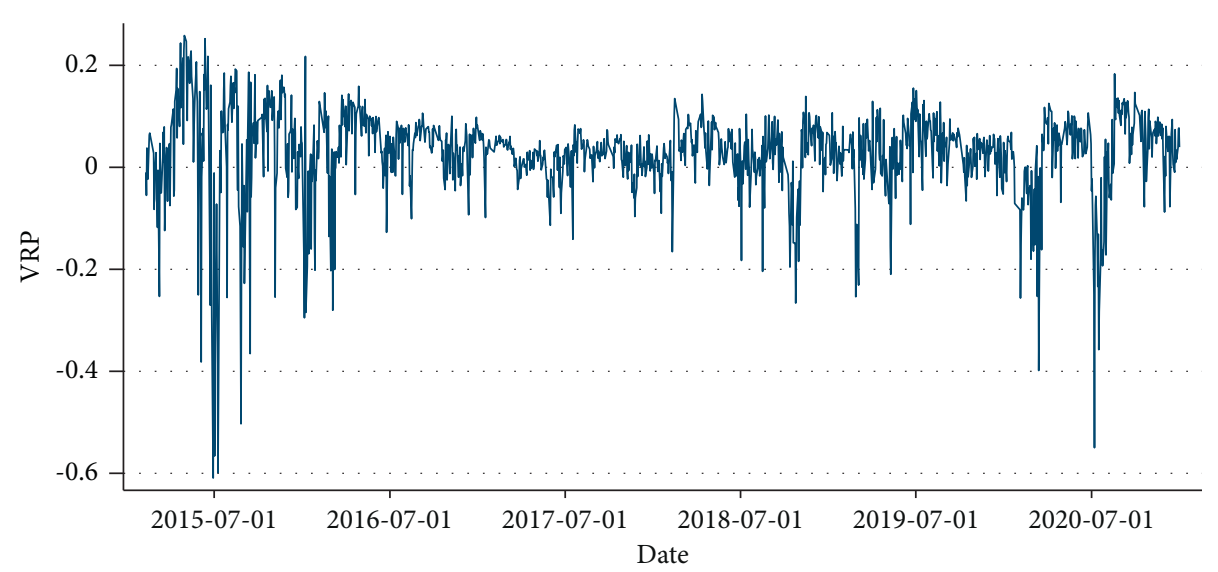

FIgURE 3: VRP original data chart of SSE 50ETF options. 
TABLE 2: Correlation analysis of variables.

\begin{tabular}{|c|c|c|c|c|c|c|c|c|}
\hline & Amihud & IV & IVS & VRP & $R_{\mathrm{F}}$ & SIR & ER & CIR \\
\hline Amihud & 1.000 & & & & & & & \\
\hline IV & $0.311^{* * *}$ & 1.000 & & & & & & \\
\hline IVS & $-0.067^{* *}$ & $-0.350^{* * *}$ & 1.000 & & & & & \\
\hline VRP & $-0.080^{* * *}$ & $-0.164^{* * *}$ & 0.015 & 1.000 & & & & \\
\hline$R_{\mathrm{F}}$ & $-0.069^{* * *}$ & $-0.192^{* * *}$ & $0.197^{* * *}$ & -0.021 & 1.000 & & & \\
\hline SIR & $-0.222^{* * *}$ & $-0.088^{* * *}$ & 0.020 & $0.062^{* *}$ & 0.008 & 1.000 & & \\
\hline ER & $-0.085^{* * *}$ & $-0.517^{* * *}$ & $0.109^{* * *}$ & $-0.071^{* * *}$ & $-0.466^{* * *}$ & 0.004 & 1.000 & \\
\hline CIR & $0.237^{* * *}$ & $0.126^{* * *}$ & $-0.063^{* *}$ & 0.036 & 0.020 & $-0.104^{* * *}$ & $-0.098^{* * *}$ & 1.000 \\
\hline VIF & & 2.45 & 1.16 & 1.14 & 2.05 & 1.02 & 2.75 & 1.03 \\
\hline
\end{tabular}

TABLE 3: Short-term forecasting power of IV on stock market liquidity.

\begin{tabular}{lccccccc}
\hline & $1 \mathrm{~d}$ & $5 \mathrm{~d}$ & $10 \mathrm{~d}$ & $30 \mathrm{~d}$ & $60 \mathrm{~d}$ & $90 \mathrm{~d}$ & $120 \mathrm{~d}$ \\
\hline $\mathrm{IV}$ & $0.133^{* * *}(9.00)$ & $0.107^{* * *}(8.75)$ & $0.118^{* * *}(7.88)$ & $0.097^{* * *}(6.47)$ & $0.069^{* * *}(4.60)$ & $0.047^{* * *}(2.85)$ & $0.038^{* * *}(3.03)$ \\
$R_{F}$ & $0.841(1.30)$ & $0.552(0.84)$ & $0.944(1.44)$ & $2.031^{* * *}(3.07)$ & $4.137^{* * *}(6.30)$ & $5.014^{* * *}(6.78)$ & $4.173^{* * *}(7.66)$ \\
SIR & $0.002(0.03)$ & $-0.053(-0.71)$ & $0.122(1.62)$ & $0.129^{*}(1.71)$ & $0.161^{*}(2.15)$ & $-0.018(-0.22)$ & $0.023(0.38)$ \\
ER & $0.017^{* * *}(2.72)$ & $0.010(1.61)$ & $0.010^{*}(1.64)$ & $0.005(0.73)$ & $0.002(0.25)$ & $0.004(0.60)$ & $0.014^{* * *}(2.77)$ \\
CIR & $0.050^{* * *}(3.65)$ & $0.034^{* * *}(2.49)$ & $0.023^{*}(1.68)$ & $0.002(0.18)$ & $0.005(0.36)$ & $-0.004(-0.25)$ & $0.013(1.13)$ \\
Adjusted $R^{2}(\%)$ & 8.49 & 6.60 & 6.27 & 4.68 & 5.89 & 4.99 & 4.66 \\
\hline
\end{tabular}

will be. On the one hand, the return of most assets in the market is based on the risk-free return rate. The rise of riskfree rate leads to the rise of investors' expected rate of return on assets, and the increase of asset price leads to the decrease of asset trading volume, which reduces the liquidity of the market. On the other hand, with the increase of risk-free interest rate, investors turn part of their investment funds to the bank deposit or bond market, weakening the liquidity of the stock market. Table 3 also reflects the regression results of the other three control variables. We also find that, compared with the risk-free rate, the prediction ability of Shanghai stock index return, CSI aggregate bond index return, and RMB exchange rate liquidity is not significant. Both SIR and CIR have positive and negative regression results. The regression coefficients of exchange rate (ER) are all positive, but they are only significant in $1 \mathrm{~d}, 10 \mathrm{~d}$, and $120 \mathrm{~d}$. This may be because the appreciation of RMB will make some investors invest in foreign financial markets, resulting in a certain degree of decline in the liquidity of China's market. However, due to the rapid development of China's financial market in recent years, the standardized regulatory system ensures the stability and security of the market. Therefore, the proportion of investors turning to foreign markets is relatively small, and the impact on liquidity is not significant enough.

Table 4 reports the medium- and long-term forecasting ability of implied volatility on stock market liquidity. Compared with the short-term range in three months, the forecasting ability is significantly reduced. It is significant at the level of $10 \%$ in $210 \mathrm{~d}$. The coefficient is negative in $240 \mathrm{~d}$ to $360 \mathrm{~d}$, which indicates that investors recognize and reflect the information contained in implied volatility in the medium and long term. In the medium and long term, the riskfree interest rate still maintains a significant forecast level. In addition, the forecast effect of exchange rate increases significantly, and the medium- and long-term regression coefficient is significantly positive, which indicates that the exchange rate contains the information of future mediumand long-term stock market liquidity.

The information in Tables 3 and 4 shows that the shortterm (within 120 days) prediction ability of implied volatility on stock market liquidity is better, and the medium- and long-term prediction effect is not significant. Hence, the short-term implied volatility is a better prediction index.

4.3.2. Forecasting Power of IVS on Stock Market Liquidity. Table 5 shows the prediction of implied volatility spread (IVS) for stock market liquidity. For the short-term time interval within three months, IVS has strong prediction ability, and the coefficients except $90 \mathrm{~d}$ are significant at $1 \%$ significance level. In the medium and long term, $270 \mathrm{~d}$ can be regarded as a watershed. Within $270 \mathrm{~d}$, the prediction ability is still strong, while the prediction ability from $270 \mathrm{~d}$ to $360 \mathrm{~d}$ is poor, and the coefficients are not significant. According to the regression results in the table, we find the implied volatility spread contains the short-term and medium-term liquidity information of the future stock market, and the coefficient is positive, indicating that the market liquidity is negatively correlated with the implied volatility spread. This may be because when IVS is greater than 0 , investors are generally optimistic about the market, so they will choose to hold stocks to bring higher returns from the rise of stock prices. The number of stocks used for trading in the market will decrease, so the liquidity of stock in the market will decline.

4.3.3. Forecasting Power of VRP on Stock Market Liquidity. Table 6 shows the ability of variance risk premium (VRP) to predict liquidity. The coefficient of VRP is significantly negative in $10 \mathrm{~d}$ and significantly positive in $30 \mathrm{~d}$ at the $5 \%$ 
TABLE 4: Medium- and long-term forecasting power of IV on stock market liquidity.

\begin{tabular}{lcccccccc}
\hline & $150 \mathrm{~d}$ & $180 \mathrm{~d}$ & $210 \mathrm{~d}$ & $240 \mathrm{~d}$ & $270 \mathrm{~d}$ & $300 \mathrm{~d}$ & $330 \mathrm{~d}$ & $360 \mathrm{~d}$ \\
\hline $\mathrm{IV}$ & $0.015(1.18)$ & $0.007(0.54)$ & $0.023^{*}(1.84)$ & $\begin{array}{c}-0.020^{*} \\
(-1.64)\end{array}$ & $\begin{array}{c}-0.010 \\
(-0.78)\end{array}$ & $\begin{array}{c}-0.005 \\
(-0.40)\end{array}$ & $\begin{array}{c}-0.018 \\
(-1.45)\end{array}$ & $\begin{array}{c}-0.033^{* *} \\
(-2.52)\end{array}$ \\
\hline$R_{F}$ & $\begin{array}{c}3.878^{* * *} \\
(7.11)\end{array}$ & $\begin{array}{c}4.279^{* * *} \\
(7.84)\end{array}$ & $\begin{array}{c}5.937^{* * *} \\
(11.04)\end{array}$ & $\begin{array}{c}4.961^{* * *} \\
(9.05)\end{array}$ & $\begin{array}{c}5.565^{* * *} \\
(9.92)\end{array}$ & $\begin{array}{c}5.316^{* * *} \\
(9.38)\end{array}$ & $\begin{array}{c}4.999^{* * *} \\
(8.81)\end{array}$ & $\begin{array}{c}3.367^{* * *} \\
(5.80)\end{array}$ \\
\hline SIR & $0.022(0.36)$ & $0.033(0.53)$ & $0.009(0.15)$ & $\begin{array}{c}-0.063 \\
(-1.05)\end{array}$ & $\begin{array}{c}-0.054 \\
(-0.89)\end{array}$ & $\begin{array}{c}-0.017 \\
(-0.27)\end{array}$ & $\begin{array}{c}-0.017 \\
(-0.27)\end{array}$ & $-0.135(-2.12)$ \\
\hline ER & $\begin{array}{c}0.015^{* * *} \\
(2.98)\end{array}$ & $\begin{array}{c}0.021^{* * *} \\
(3.99)\end{array}$ & $\begin{array}{c}0.036^{* * *} \\
(6.98)\end{array}$ & $\begin{array}{c}0.030^{* * *} \\
(5.85)\end{array}$ & $\begin{array}{c}0.039^{* * *} \\
(7.50)\end{array}$ & $\begin{array}{c}0.043^{* * *} \\
(8.21)\end{array}$ & $\begin{array}{c}0.044^{* * *} \\
(8.32)\end{array}$ & $\begin{array}{c}0.039^{* * *} \\
(7.25)\end{array}$ \\
\hline $\mathrm{CIR}$ & -0.003 & $0.008(0.67)$ & $0.008(0.73)$ & $0.009(0.82)$ & $\begin{array}{c}-0.010 \\
(-0.87)\end{array}$ & $\begin{array}{c}-0.012 \\
(-1.03)\end{array}$ & $0.012(0.95)$ & $0.006(0.50)$ \\
\hline $\begin{array}{l}\text { Adjusted } R^{2} \\
(\%)\end{array}$ & $(-0.25)$ & 5.28 & 10.92 & 12.78 & 15.40 & 15.70 & 17.47 & 15.00 \\
\hline
\end{tabular}

TABLE 5: Forecasting power of IVS on stock market liquidity.

\begin{tabular}{|c|c|c|c|c|c|c|c|c|}
\hline \multicolumn{9}{|c|}{ Panel A: short-term forecasting power of IVS on stock market liquidity } \\
\hline & $1 \mathrm{~d}$ & $5 \mathrm{~d}$ & $10 \mathrm{~d}$ & $30 \mathrm{~d}$ & $60 \mathrm{~d}$ & $90 \mathrm{~d}$ & $120 \mathrm{~d}$ & \\
\hline IVS & $\begin{array}{c}0.032^{* * *} \\
(2.76)\end{array}$ & $\begin{array}{c}0.037^{* * *} \\
(3.18)\end{array}$ & $\begin{array}{c}0.048^{* * *} \\
(4.19)\end{array}$ & $\begin{array}{c}0.062^{* * *} \\
(5.43)\end{array}$ & $\begin{array}{c}0.051^{* * *} \\
(4.45)\end{array}$ & $\begin{array}{c}0.026^{* *} \\
(2.00)\end{array}$ & $\begin{array}{c}0.023^{* *} \\
(2.43)\end{array}$ & \\
\hline$R_{F}$ & $\begin{array}{c}-2.941^{* * *} \\
(-5.19)\end{array}$ & $\begin{array}{c}-2.825^{* * *} \\
(-4.97)\end{array}$ & $\begin{array}{c}-2.686^{* * *} \\
(-4.73)\end{array}$ & $\begin{array}{c}-1.283^{* *} \\
(-2.26)\end{array}$ & $\begin{array}{c}1.707^{* * *} \\
(3.05)\end{array}$ & $\begin{array}{c}3.476^{* * *} \\
(5.49)\end{array}$ & $\begin{array}{c}2.856^{* * *} \\
(6.20)\end{array}$ & \\
\hline SIR & $-0.071(-0.94)$ & $-0.117(-1.55)$ & $0.055(0.72)$ & $0.072(0.95)$ & $0.121(1.61)$ & $\begin{array}{l}-0.048 \\
(-0.59)\end{array}$ & $0.000(0.01)$ & \\
\hline ER & $\begin{array}{c}-0.025^{* * *} \\
(-5.33)\end{array}$ & $\begin{array}{c}-0.262^{* * *} \\
(-5.69)\end{array}$ & $-0.028(-6.10)$ & $\begin{array}{l}-0.029 \\
(-6.33)\end{array}$ & $\begin{array}{l}-0.023 \\
(-5.02)\end{array}$ & $\begin{array}{l}-0.013 \\
(-2.65)\end{array}$ & $0.001(0.24)$ & \\
\hline CIR & $\begin{array}{c}0.061^{* * *} \\
(4.35)\end{array}$ & $0.044^{* *}(3.16)$ & $0.034^{* *}(2.43)$ & $0.013(0.91)$ & $0.012(0.91)$ & $0.002(0.09)$ & $0017(1.51)$ & \\
\hline $\begin{array}{l}\text { Adjusted } R^{2} \\
(\%)\end{array}$ & 3.82 & 3.46 & 3.39 & 3.88 & 5.80 & 4.66 & 4.43 & \\
\hline \multicolumn{9}{|c|}{ Panel B: medium- and long-term forecasting power of IVS on stock market liquidity } \\
\hline & $150 \mathrm{~d}$ & $180 \mathrm{~d}$ & $210 \mathrm{~d}$ & $240 \mathrm{~d}$ & $270 \mathrm{~d}$ & $300 \mathrm{~d}$ & $330 \mathrm{~d}$ & $360 \mathrm{~d}$ \\
\hline IVS & $\begin{array}{c}0.048^{* * *} \\
(5.04)\end{array}$ & $\begin{array}{c}0.047^{* * *} \\
(4.78)\end{array}$ & $0.025^{* *}(2.53)$ & $0.034(1.63)$ & $\begin{array}{c}0.025^{* * *} \\
(2.60)\end{array}$ & $0.009(0.89)$ & $\begin{array}{l}-0.003 \\
(-0.29)\end{array}$ & $0.008(0.78)$ \\
\hline$R_{F}$ & $\begin{array}{c}2.809^{* * *} \\
(6.15)\end{array}$ & $\begin{array}{c}3.460^{* * *} \\
(7.57)\end{array}$ & $\begin{array}{c}5.007^{* * *} \\
(10.89)\end{array}$ & $\begin{array}{c}5.616^{* * *} \\
(12.39)\end{array}$ & $\begin{array}{c}5.475^{* * *} \\
(11.45)\end{array}$ & $\begin{array}{c}5.318^{* * *} \\
(10.94)\end{array}$ & $\begin{array}{c}5.498^{* * *} \\
(11.31)\end{array}$ & $\begin{array}{c}4.074^{* * *} \\
(8.18)\end{array}$ \\
\hline SIR & $0.008(0.14)$ & $0.023(0.37)$ & $-0.009(-0.14)$ & $\begin{array}{l}-0.030 \\
(-0.49)\end{array}$ & $\begin{array}{l}-0.051 \\
(-0.85)\end{array}$ & $\begin{array}{l}-0.014 \\
(-0.23)\end{array}$ & $\begin{array}{l}-0.005 \\
(-0.09)\end{array}$ & $\begin{array}{c}-0.118^{*} \\
(-1.85)\end{array}$ \\
\hline ER & $0.006^{*}(1.74)$ & $\begin{array}{c}0.014^{* * *} \\
(3.78)\end{array}$ & $\begin{array}{c}0.027^{* * *} \\
(7.23)\end{array}$ & $\begin{array}{c}0.036^{* * *} \\
(10.33)\end{array}$ & $\begin{array}{c}0.039^{* * *} \\
(10.78)\end{array}$ & $\begin{array}{c}0.044^{* * *} \\
(11.91)\end{array}$ & $\begin{array}{c}0.051^{* * *} \\
(13.48)\end{array}$ & $\begin{array}{c}0.049^{* * *} \\
(12.44)\end{array}$ \\
\hline CIR & $0.002(0.15)$ & $0.012(1.11)$ & $0.012(1.06)$ & $\begin{array}{l}-0.006 \\
(-0.52)\end{array}$ & $\begin{array}{l}-0.009 \\
(-0.82)\end{array}$ & $\begin{array}{l}-0.013 \\
(-1.04)\end{array}$ & $0.010(0.82)$ & $0.003(0.21)$ \\
\hline $\begin{array}{l}\text { Adjusted } R^{2} \\
(\%)\end{array}$ & 5.94 & 7.49 & 11.11 & 12.79 & 15.81 & 15.75 & 17.47 & 14.74 \\
\hline
\end{tabular}

significance level. This may be, because when the variance risk premium rises, investors' aversion to risk rises, and they choose to trade in the market to reduce their holdings. After a period of time, they usually reduce trading to wait for better opportunities. After 30 days, there was no significant predictive ability. Generally speaking, VRP contains less information about future stock market liquidity and has no significant ability to predict market liquidity.

Comparing the regression results of IV, IVS, and VRP, we confirm that both implied volatility and implied volatility spread can predict the liquidity level of short-term stock market, and both are good predictors. For the medium-term time interval, IVS is better than IV, which indicates that implied volatility spread contains information about market liquidity for a longer time, which implied volatility does not have. For the time interval of more than 270 days, both of them did not show good prediction ability. In contrast, variance risk premium has no significant ability to predict stock market liquidity.

4.3.4. Forecasting Power of Weekly and Monthly Data on Stock Market Liquidity. Referring to the research of Han and $\mathrm{Li}$ [38], there are differences in the information contained in the data of different time dimensions. Therefore, this section examines the ability of weekly and monthly IV, IVS, and VRP to predict the liquidity of the stock market. 
TABLE 6: Forecasting power of VRP on stock market liquidity.

\begin{tabular}{|c|c|c|c|c|c|c|c|c|}
\hline \multicolumn{9}{|c|}{ Panel A: short-term forecasting power of VRP on stock market liquidity } \\
\hline & $1 \mathrm{~d}$ & $5 \mathrm{~d}$ & $10 \mathrm{~d}$ & $30 \mathrm{~d}$ & $60 \mathrm{~d}$ & $90 \mathrm{~d}$ & $120 \mathrm{~d}$ & \\
\hline VRP & $\begin{array}{c}-0.051^{* * *} \\
(-4.08)\end{array}$ & $\begin{array}{c}-0.042^{* * *} \\
(-3.35)\end{array}$ & $\begin{array}{c}-0.038^{* * *} \\
(-2.99)\end{array}$ & $0.025^{* *}(1.98)$ & $\begin{array}{l}-0.001 \\
(-0.03)\end{array}$ & $0.010(0.91)$ & $\begin{array}{l}-0.004 \\
(-0.43)\end{array}$ & \\
\hline$R_{F}$ & $\begin{array}{c}-2.640^{* * *} \\
(-4.86)\end{array}$ & $\begin{array}{c}-2.432^{* * *} \\
(-4.45)\end{array}$ & $\begin{array}{c}-2.120^{* * *} \\
(-3.87)\end{array}$ & $\begin{array}{l}-0.354 \\
(-0.64)\end{array}$ & $\begin{array}{c}2.404^{* * *} \\
(4.43)\end{array}$ & $\begin{array}{c}2.879^{* * *} \\
(5.78)\end{array}$ & $\begin{array}{c}3.177^{* * *} \\
(7.25)\end{array}$ & \\
\hline SIR & $\begin{array}{l}-0.048 \\
(-0.64)\end{array}$ & $-0.097(-1.28)$ & $0.074(0.97)$ & $0.067(0.88)$ & $0.125^{*}(1.66)$ & $0.024(0.35)$ & $0.006(0.09)$ & \\
\hline ER & $\begin{array}{c}-0.023^{* * *} \\
(-5.19)\end{array}$ & $\begin{array}{c}-0.024^{* * *} \\
(-5.38)\end{array}$ & $\begin{array}{c}-0.025^{* * *} \\
(-5.52)\end{array}$ & $\begin{array}{c}-0.023^{* * *} \\
(-5.00)\end{array}$ & $\begin{array}{c}-0.018^{* * *} \\
(-4.08)\end{array}$ & $\begin{array}{c}-0.008^{*} \\
(-1.86)\end{array}$ & $0.003(0.82)$ & \\
\hline CIR & $\begin{array}{c}0.061^{* * *} \\
(4.39)\end{array}$ & $\begin{array}{c}0.044^{* * *} \\
(3.14)\end{array}$ & $0.033^{* *}(2.34)$ & $0.008(0.59)$ & $0.010(0.70)$ & $\begin{array}{l}-0.010 \\
(-0.75)\end{array}$ & $0.016(1.40)$ & \\
\hline $\begin{array}{l}\text { Adjusted } R^{2} \\
(\%) \\
\end{array}$ & 4.42 & 3.54 & 2.81 & 2.17 & 4.49 & 3.78 & 4.05 & \\
\hline \multicolumn{9}{|c|}{ Panel B: medium- and long-term forecasting power of VRP on stock market liquidity } \\
\hline & $150 \mathrm{~d}$ & $180 \mathrm{~d}$ & $210 \mathrm{~d}$ & $240 \mathrm{~d}$ & $270 \mathrm{~d}$ & $300 \mathrm{~d}$ & $330 \mathrm{~d}$ & $360 \mathrm{~d}$ \\
\hline VRP & $-0.012(-1.17)$ & $\begin{array}{l}-0.009 \\
(-0.86)\end{array}$ & $-0.004-0.37)$ & $-0.001(-0.10)$ & $0.004(0.37)$ & $0.011(1.01)$ & $0.008(0.76)$ & $0.007(0.58)$ \\
\hline$R_{F}$ & $\begin{array}{c}3.457^{* * *} \\
(7.92)\end{array}$ & $\begin{array}{c}4.082^{* * *} \\
(9.33)\end{array}$ & $\begin{array}{c}5.315^{* * *} \\
(12.28)\end{array}$ & $\begin{array}{c}5.335^{* * *} \\
(12.28)\end{array}$ & $\begin{array}{c}5.790^{* * *} \\
(12.79)\end{array}$ & $\begin{array}{c}5.491^{* * *} \\
(11.83)\end{array}$ & $\begin{array}{c}5.504^{* * *} \\
(11.80)\end{array}$ & $\begin{array}{c}4.240^{* * *} \\
(8.87)\end{array}$ \\
\hline SIR & $0.019(0.31)$ & $0.033(0.54)$ & $\begin{array}{l}-0.001 \\
(-0.02)\end{array}$ & $\begin{array}{l}-0.050 \\
(-0.83)\end{array}$ & $\begin{array}{l}-0.050 \\
(-0.83)\end{array}$ & $\begin{array}{l}-0.020 \\
-0.33)\end{array}$ & $\begin{array}{l}-0.013 \\
(-0.21)\end{array}$ & $\begin{array}{c}-0.120^{*} \\
(-1.89)\end{array}$ \\
\hline ER & $\begin{array}{c}0.011^{* * *} \\
(2.96)\end{array}$ & $\begin{array}{c}0.019^{* * *} \\
(5.15)\end{array}$ & $\begin{array}{c}0.029^{* * *} \\
(8.29)\end{array}$ & $\begin{array}{c}0.036^{* * *} \\
(10.34)\end{array}$ & $\begin{array}{c}0.042^{* * *} \\
(12.11)\end{array}$ & $\begin{array}{c}0.045^{* * *} \\
(12.80)\end{array}$ & $\begin{array}{c}0.049^{* * *} \\
(13.85)\end{array}$ & $\begin{array}{c}0.048^{* * *} \\
(12.97)\end{array}$ \\
\hline CIR & $-0.001(-0.11)$ & $0.009(0.76)$ & $0.010(0.90)$ & $\begin{array}{l}-0.004 \\
(-0.31)\end{array}$ & $\begin{array}{l}-0.011 \\
(-0.95)\end{array}$ & $\begin{array}{l}-0.014 \\
(-1.11)\end{array}$ & $0.009(0.72)$ & $0.002(0.13)$ \\
\hline $\begin{array}{l}\text { Adjusted } R^{2} \\
(\%)\end{array}$ & 4.28 & 5.95 & 10.67 & 12.43 & 15.36 & 15.74 & 17.20 & 14.34 \\
\hline
\end{tabular}

TABLE 7: Forecasting power of weekly and monthly IV, IVS, and VRP on market liquidity.

\begin{tabular}{cccccccccc}
\hline & 4 weeks & 8 weeks & 12 weeks & 16 weeks & 1 months & 2 months & 3 months & 4 months \\
\hline $\mathrm{IV}_{W}$ & $\begin{array}{c}0.111^{* * *} \\
(7.30)\end{array}$ & $\begin{array}{c}0.087^{* * *} \\
(5.55)\end{array}$ & $0.072^{* *}(4.48)$ & $\begin{array}{c}0.035^{* *} \\
(2.22)\end{array}$ & $\mathrm{IV}_{m}$ & $\begin{array}{c}0.180^{* * *} \\
(5.70)\end{array}$ & $\begin{array}{c}0.138^{* * *} \\
(3.98)\end{array}$ & $\begin{array}{c}0.108^{* * *} \\
(2.99)\end{array}$ & $\begin{array}{c}0.063^{* *} \\
(2.11)\end{array}$ \\
\hline $\mathrm{IVS}_{W}$ & $0.033^{*}(1.87)$ & $\begin{array}{c}0.059^{* * *} \\
(3.36)\end{array}$ & $\begin{array}{c}0.057^{* * *} \\
(3.21)\end{array}$ & $0.027(1.57)$ & $\mathrm{IVS}_{m}$ & $0.051(1.06)$ & $0.069(1.44)$ & $0.061(1.28)$ & $0.033(0.86)$ \\
\hline $\mathrm{VRP}_{W}$ & $0.058^{* *}(2.34)$ & $0.020(0.82)$ & $\begin{array}{c}-0.003 \\
(-0.30)\end{array}$ & $0.006(0.25)$ & $\mathrm{VRP}_{m}$ & $0.085(1.10)$ & $\begin{array}{c}-0.011 \\
(-0.14)\end{array}$ & $\begin{array}{c}-0.010 \\
(-0.13)\end{array}$ & $0.010(0.16)$ \\
\hline
\end{tabular}

Note. IV $\mathrm{IV}_{W} \mathrm{IVS}_{W}$, and $\mathrm{VRP}_{W}$ are weekly IV, IVS, and VRP; IV $\mathrm{IVS}_{m}$, and $\mathrm{VRP}_{m}$ are monthly IV, IVS, and VRP, respectively.

Table 7 reports the forecasting ability of weekly and monthly IV, IVS, and VRP. The weekly and monthly data of implied volatility still maintain a relatively stable forecasting effect, indicating that the low-frequency implied volatility still contains the liquidity information of the stock market in the next four months. The forecasting effect of implied volatility spread has declined, and the forecasting ability of weekly data in liquidity is still significant. At the same time, the coefficient of IVS $_{m}$ is positive, but it is not significant. This may be because the value of IVS is positive and negative and, with lower frequency of data, the related information may be offset, which reduces the forecasting ability of IVS. Therefore, the higher the frequency of data, the better the prediction effect for the implied volatility spread. In contrast, the weekly and monthly variance risk premium is still unable to predict the liquidity in the stock market.
4.4. Robustness Test. In order to test the reliability of the above empirical results, the three following kinds of robustness tests are carried out to examine the reliability of IVS on the liquidity prediction ability of the stock market.

4.4.1. Phased Regression Analysis. As can be seen from Figure 2, in the early stage of the introduction of SSE 50ETF options, the parity relationship of put and call options deviated seriously, and IVS was obviously different from 0 . Therefore, this section attempts to explore whether IVS had different liquidity forecasts in different periods. In order to find the liquidity information contained in IVS, the sample period is divided into two parts: the early stage of development (February 9, 2015, to December 31, 2017) and the development period (January 1, 2018, to December 31, 2020). 


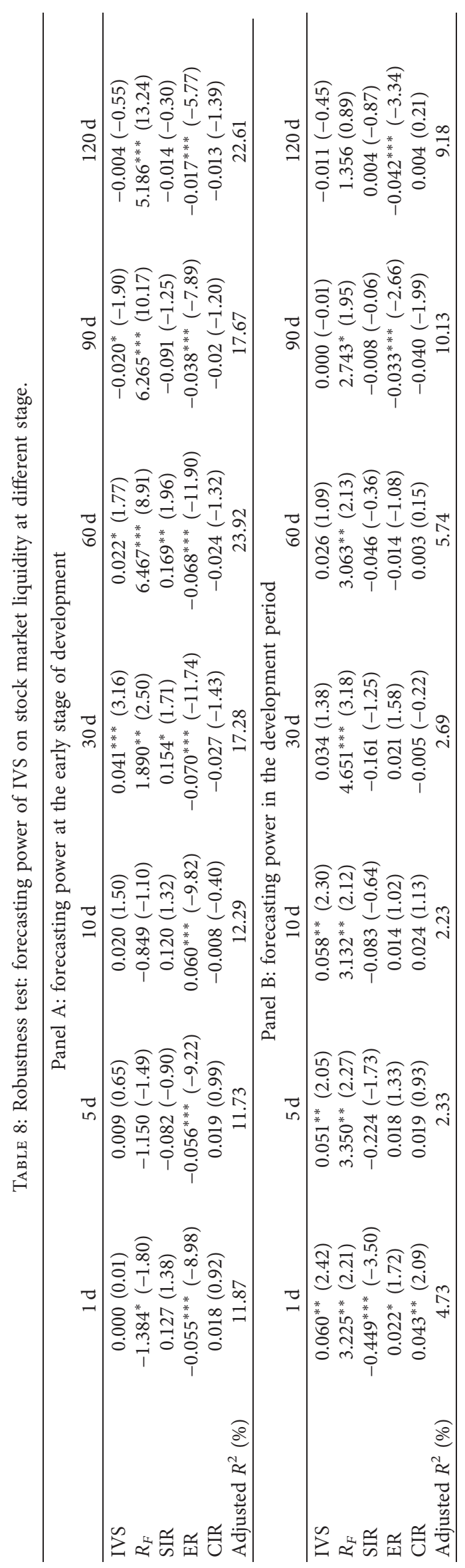


TABLE 9: Robustness test: forecasting power of volume weighted IVS on stock market liquidity.

\begin{tabular}{ccccccccc}
\hline & $1 \mathrm{~d}$ & $5 \mathrm{~d}$ & $10 \mathrm{~d}$ & $30 \mathrm{~d}$ & $60 \mathrm{~d}$ & $90 \mathrm{~d}$ & $120 \mathrm{~d}$ & $150 \mathrm{~d}$ \\
\hline IVS & $0.014(1.34)$ & $0.021^{* *}(1.99)$ & $0.033^{* * *}(3.08)$ & $0.040^{* * *}(3.78)$ & $0.035^{* * *}(3.39)$ & $0.008(0.85)$ & $0.020^{* *}(2.06)$ & $0.045^{* * *}(4.57)$ \\
\hline & $180 \mathrm{~d}$ & $210 \mathrm{~d}$ & $240 \mathrm{~d}$ & $270 \mathrm{~d}$ & $300 \mathrm{~d}$ & $330 \mathrm{~d}$ & $360 \mathrm{~d}$ \\
\hline IVS & $0.044^{* * *}(4.08)$ & $0.037^{* * *}(3.18)$ & $0.035^{* * *}(2.96)$ & $0.032^{* * *}(2.69)$ & $-0.006(-0.45)$ & $-0.002(-0.19)$ & $0.009(0.71)$ \\
\hline
\end{tabular}

TABLE 10: Robustness test: based on turnover IVS to predict the liquidity of stock market.

\begin{tabular}{ccccccccc}
\hline & $1 \mathrm{~d}$ & $5 \mathrm{~d}$ & $10 \mathrm{~d}$ & $30 \mathrm{~d}$ & $60 \mathrm{~d}$ & $90 \mathrm{~d}$ & $120 \mathrm{~d}$ & $150 \mathrm{~d}$ \\
\hline \multirow{2}{*}{$\mathrm{IVS}$} & $\begin{array}{c}-0.728^{* * *} \\
(-3.02)\end{array}$ & $\begin{array}{c}-0.642^{* * *} \\
(-2.65)\end{array}$ & $\begin{array}{c}-0.489^{* *} \\
(-2.00)\end{array}$ & $\begin{array}{c}-0.627^{* *} \\
(-2.50)\end{array}$ & $\begin{array}{c}-0.744^{* * *} \\
(-2.85)\end{array}$ & $\begin{array}{c}-0.171 \\
(-0.69)\end{array}$ & $\begin{array}{c}-0.634^{* * *} \\
(-2.79)\end{array}$ & $\begin{array}{c}-0.481^{* *} \\
(-2.3)\end{array}$ \\
\hline & $180 \mathrm{~d}$ & $210 \mathrm{~d}$ & $240 \mathrm{~d}$ & $270 \mathrm{~d}$ & $300 \mathrm{~d}$ & $330 \mathrm{~d}$ & $360 \mathrm{~d}$ \\
\hline \multirow{2}{*}{ IVS } & $\begin{array}{c}-0.476^{* *} \\
(-2.38)\end{array}$ & $\begin{array}{c}-0.577^{* * *} \\
(-3.08)\end{array}$ & $\begin{array}{c}-0.435^{* *} \\
(-2.44)\end{array}$ & $-0.049(-0.27)$ & $-0.355^{*}(-1.89)$ & $\begin{array}{c}0.601^{* * *} \\
(3.24)\end{array}$ & $-0.043(-0.23)$ \\
\hline
\end{tabular}

Table 8 shows the forecasting effect of IVS of SSE 50ETF options in different development periods. In the early stage of development, the market pricing efficiency is low, and IVS contains less market information, so the early prediction ability is low, and the prediction effect for the stock market liquidity within the next 30 days is not significant. For the development period, the forecast effect is better than that in the initial stage, which shows that, with the continuous development of SSE 50ETF options, the market pricing efficiency gradually improves, and the forecast effect tends to be stable.

4.4.2. Adjust the Calculation Method of IVS. Nikolaos and Thanos [39] pointed out that the trading volume of options likely reflects market information flows and investors' expectations about specific types of movements of the underlying market index. Therefore, in this section, IVS is calculated based on the trading volume of options on the same day to examine the robustness of the conclusion:

$$
\mathrm{IVS}_{t}=\mathrm{IV}_{t}^{\text {call }}-\mathrm{IV}_{t}^{\mathrm{put}}=\sum_{j=1}^{N_{t}} w_{j}\left(\mathrm{IV}_{j}^{\text {calls }}-\mathrm{IV}_{j, t}^{\text {puts }}\right),
$$

where $W_{j}$ is the weight of the trading volume of the pair of options $j$ on day $t$ in the total trading volume of that day, and the rest is the same as formula (3).

Table 9 reports the IVS regression results based on the weighted calculation of trading volume. We confirm that the prediction of implied volatility spread on the liquidity of stock market is still significant. Compared with the IVS based on the weighted calculation of open position, only the coefficients of $1 \mathrm{~d}$ and $90 \mathrm{~d}$ are not significant. The other time intervals within $270 \mathrm{~d}$ are significant, indicating that the prediction power of IVS on liquidity is reliable and robust.

4.4.3. Change the Liquidity Index of Stock Market. Referring to the researches of Abdulrahman and Atsuyuki [25] and Karen et al. [40], we use turnover rate to measure the liquidity of stock market, which refers to the ratio of share turnover calculated by the sum of share volumes of stock $i$ on day $d$.

$$
\begin{aligned}
\operatorname{Turn}_{i, d} & =\frac{\text { share volume }_{i, d}}{\text { share out }_{i, d}} \times 100, \\
\operatorname{Turn}_{m, d} & =\frac{1}{N} \sum_{t=1}^{N} \operatorname{Turn}_{i, d},
\end{aligned}
$$

where $N$ is the number of stocks normally traded in the A-share market, excluding the stocks of ST, ST*, and PT companies.

Through turnover rate to measure liquidity, the regression results are shown in Table 10. We find that the results are robust. IVS still contains information about the liquidity of the stock market in the future. It has a significant ability to predict liquidity in the short-term and mediumterm markets. The coefficient is negative, indicating that there is a negative correlation between the two.

\section{Conclusions and Discussion}

By analyzing the implied information of SSE 50ETF options, including implied volatility, implied volatility spread, and variance risk premium, this paper investigates its ability to predict stock market liquidity. Implied volatility contains the information of short-term (120 days) liquidity of stock market. It shows that IV and IVS are good indicators to predict the liquidity of the stock market. In contrast, variance risk premium (VRP) cannot significantly predict the liquidity of the stock market. At the same time, the influence of different frequency index data on the prediction effect is also considered. The regression results show that the prediction effect of weekly data and monthly data is lower than that of daily data, indicating that the daily data has the strongest prediction ability. In addition, in order to examine the reliability of the relevant conclusions, the robustness test of the prediction ability of implied volatility spread is still valid.

The options market plays a role in sharing and transferring risks, representing investors' views on the future of the market, including information about the stock market's future. Liquidity is a vital attribute reflecting the quality of the market, and liquidity risk is increasingly concerned by market participants. The implied information of options has 
a significant ability to predict the liquidity of the stock market. Therefore, investors should pay full attention to the implied information of options, learn the knowledge of options theory, and actively use the implied information to trade at the right time to achieve the purpose of reducing risk.

\section{Data Availability}

The data were taken from the CSMAR and RESSET databases.

\section{Conflicts of Interest}

The authors declare no conflicts of interest.

\section{Acknowledgments}

This research was jointly funded by NSFC funded project "Modeling and application of stock portfolio risk based on dynamic copula and realized volatility theory under high frequency data" (71701104), Ministry of Education for Humanities and Social Science Foundation "Research on dynamic extreme value risk measurement and its application of copula model based on high-frequency big data" (17YJC790102), General Project of Jiangsu Social Science Foundation "Research on dynamic risk transmission relationship between cryptocurrency index and RMB exchange rate index in the context of blockchain" (20GLB008), and Jiangsu University Philosophy and Social Science Foundation Project "Research on innovation and development mechanism of science and technology finance based on Internet financial framework" (2019SJA0153).

\section{References}

[1] Y. Amihud and H. Mendelson, "Asset pricing and the bid-ask spread," Journal of Financial Economics, vol. 17, no. 2, pp. 223-249, 1986.

[2] O. Bondarenko, "Competing market makers, liquidity provision and bid-ask spread," Journal of Financial Markets, vol. 4, no. 1, pp. 269-308, 2001.

[3] L. Harris, Liquidity, Trading Rules, and Electronic Trading Systems, New York University, New York, NY, USA, 1990.

[4] P. Brockman and D. Y. Chung, "Commonality in liquidity: evidence from an order-driven market structure," Journal of Financial Research, vol. 25, no. 4, pp. 521-539, 2002.

[5] Y. Amihud, "Illiquidity and stock returns: cross-section and time-series effects," Journal of Financial Markets, vol. 5, no. 1, pp. 31-56, 2002.

[6] S. Lippman and J. McCall, "An operational measure of liquidity," The American Economic Eeview, vol. 76, no. 1, pp. 43-55, 1986.

[7] Y. Amihud and H. Mendelson, "The effects of beta, bid-ask spread, residual risk, and size on stock returns," The Journal of Finance, vol. 44, no. 2, pp. 479-486, 1989.

[8] Y. Ji, X. Jin, Z. Xu, and S. Qu, “A mixed 0-1 programming approach for multiple attribute strategic weight manipulation based on uncertainty theory," Journal of Intelligent and Fuzzy Systems, vol. 41, 2021.

[9] G. Bakshi, N. Kapadia, and D. Madan, "Stock return characteristics, skew laws, and the differential pricing of individual equity options," Review of Financial Studies, vol. 16, no. 1, pp. 101-143, 2003.

[10] T. Chen and S. Wang, "Incomplete information model of credit default of micro and small enterprises," International Journal of Finance and Economics, vol. 26, 2021.

[11] Y. Ji, H. Li, and H. Zhang, "Risk-averse two-stage stochastic minimum cost consensus models with asymmetric adjustment cost," Group Decision and Negotiation, vol. 30, 2021.

[12] T. G. Bali and A. Hovakimian, "Volatility spreads and expected stock returns," Management Science, vol. 55, no. 11, pp. 1797-1812, 2009.

[13] T. Bollerslev, J. Marrone, L. Xu, and H. Zhou, "Stock return predictability and variance risk premia: statistical inference and international evidence," Journal of Financial and Quantitative Analysis, vol. 49, no. 3, pp. 633-661, 2014.

[14] C.-H. Chen, H. Chung, and S.-F. Yuan, "Deviations from putcall parity and volatility prediction: evidence from the Taiwan index option market," Journal of Futures Markets, vol. 34, no. 12, pp. 1122-1145, 2014.

[15] C. Cao, S. Timothy, and X. Han, "Predicting the equity premium with the implied volatility spread," Journal of Financial Markets, vol. 51, Article ID 100531, 2019.

[16] P. Marcel and W. Chardin, "The importance of the volatility risk premium for volatility forecasting," Journal of Banking and Finance, vol. 40, pp. 303-320, 2014.

[17] P. Henrique and B. Marcelo, "Liquidity, implied volatility and tail risk: a comparison of liquidity measures," International Review of Financial Analysis, vol. 69, Article ID 101463, 2020.

[18] H. Demsetz, "The cost of transacting," The Quarterly Journal of Economics, vol. 82, no. 1, pp. 33-53, 1968.

[19] F. Black, "Towards a full automated exchange," Financial Analysts Journal, vol. 27, pp. 29-35, 1971

[20] A. S. Kyle, "Continuous auctions and insider trading," Econometrica, vol. 53, no. 6, pp. 1315-1335, 1985.

[21] S. Grossman, "Liquidity and market structure," The Journal of Finance, vol. 43, no. 3, pp. 619-637, 1988.

[22] P. Martin, "Analysis of the impact of competitive rates on the liquidity of NYSE stocks," Economic Staff Paper, vol. 75, no. 3, 1975.

[23] A. Ignacio and A. A. Diego, "How does information disclosure affect liquidity? evidence from an emerging market," The North American Journal of Economics and Finance, vol. 50, Article ID 100997, 2019.

[24] K. Jyoti, "Investor sentiment and stock market liquidity: evidence from an emerging economy," Journal of Behavioral and Experimental Finance, vol. 23, pp. 166-180, 2019.

[25] A. Abdulrahman and N. Atsuyuki, "Corporate future investments and stock liquidity: evidence from emerging markets," International Review of Economics and Finance, vol. 65, pp. 69-83, 2020.

[26] M. Bai and Y. Qin, "Commonality in liquidity in emerging markets: another supply-side explanation," International Review of Economics and Finance, vol. 39, no. 6, pp. 90-106, 2014.

[27] L. Cao and G. Kling, "Regulatory changes and market liquidity in Chinese stock market," Emerging Markets Review, vol. 7, no. 2, pp. 162-175, 2006.

[28] A. Basistha and A. Kurov, "Macroeconomic cycles and the stock market's reaction to monetary policy," Journal of Banking \& Finance, vol. 32, no. 12, pp. 2606-2616, 2008.

[29] Z. Dai, J. Kang, and F. Wen, "Predicting stock returns: a risk measurement perspective," International Review of Financial Analysis, vol. 74, Article ID 101676, 2021. 
[30] M. Britten-Jones and A. Neuberger, "Option prices, implied price processes, and stochastic volatility," The Journal of Finance, vol. 55, no. 2, pp. 839-866, 2000.

[31] M. Cremers and D. Weinbaum, "Deviations from put-call parity and stock return predictability," Journal of Financial and Quantitative Analysis, vol. 45, no. 2, pp. 335-367, 2010.

[32] T. Bollerslev, T. George, and Z. Hao, "Expected stock returns and variance risk premia," The Review of Financial Studies, vol. 22, no. 11, pp. 4464-4492, 2009.

[33] X. Wan, C. Yang, and D. Lv, "An evaluation of low-frequency liquidity proxies: an empirical analysis based on the Chinese stock market," Forecasting, vol. 37, no. 2, pp. 50-55, 2018.

[34] P. A. Griffin, D. H. Lont, and K. Purdon, "Stock and bond return comovement as a different way to assess information content: the case of debt covenant violation disclosures," Abacus, vol. 57, no. 1, pp. 101-125, 2021.

[35] P. Marcello, "On risk factors of the stock and bond correlation," International Finance, vol. 23, no. 3, pp. 392-416, 2020.

[36] S. Long, M. Zhang, and K. Li, "Do the RMB exchange rate and global commodity prices have asymmetric or symmetric effects on China's stock prices," Financial Innovation, vol. 7, no. 1, pp. 1-21, 2021.

[37] Q. Huang, X. Wang, and S. Zhang, "The effects of exchange rate fluctuations on the stock market and the affecting mechanisms: evidence from BRICS countries," The North American Journal of Economics and Finance, vol. 56, Article ID 101340, 2021.

[38] B. Han and G. Li, "Information content of aggregate implied volatility spread," Management Science, vol. 67, no. 2, pp. 1249-1269, 2020.

[39] V. Nikolaos and V. Thanos, "Option-implied information and stock herding," International Journal of Finance and Economics, vol. 24, no. 4, pp. 1-14, 2019.

[40] M. Y. Karen, S. Walid, X. Zhu, and Y. Liu, "Political institutions, stock market liquidity and firm dividend policy: some international evidence," Journal of Contemporary Accounting \& Economics, vol. 16, no. 1, Article ID 100180, 2020. 